\title{
A studying of the University Curriculum of the Farhangian Studies And it's Relationship with the Sustainable Development
}

\author{
Zohreh Meshkibaf Moghaddam ${ }^{1}$ Ahmad Akbari $^{2}$, Moslem Cherabin ${ }^{3}$, Rayhane Fatehi $^{4}$
}

1 Director of Education Department of Hasheminejad Campus. University of Farangian Iran (z.mmoghadam@gmail.com)

${ }^{2}$ Assistant Professor of Islamic Azad University, Bardskan Branch. Professor of Neishabour Science and Research (akbari.180gmail.com)

${ }^{3}$ Assistant Professor of Islamic Azad University, Neishabour Sciences Research Branch (moslemch2015@gmail.com)

${ }^{4}$ Student management education. Deputy Researcher Academic School of Technology, Department of Education, District 5 of Mashhad (Rayhane.fattehi@gmail.com)

\section{ARTICLE INFO}

\section{Keywords:}

Sustainable Development

Farhangian University

Course Descriptions

\begin{abstract}
The purpose of the this study was to inestigate the configuration between the university fields of the Farhangian and the syllabus of the courses with the strengthening of the sustainable development which is conducted using "Document Research" and "Development Critique". The research is classified into three levels. The first level is the theoretical topics which are studied through investigating study, the study papers and the library of theoretical capacity. After decoding, the components of sustainable development of extraction are studied, and the axial encoding is done thorough examination of academic courses and content. On the third level, the setting of the components of study and conceptualizations are discussed below the concepts. Finally, the results get analyzed. The results indicate that some of the titles are clearly defined, and some of them are implicitly and subtly aligned with the "social", "organizational" and "technological" sustainability concepts. However, the economic and biological sustainability are not the focus of the content. Besides, the content of some subjects do not mention any sustainable development. On the other hand, given the fact that the foundation for sustainable development is the strengthening of professional technical courses, the Farhangian University is specialized in training teachers in theoretical fields; and except for the "Academic School Physical Education instructor", it does not cover the "Vocational Physical Education instructor".
\end{abstract}

\section{Introduction}

Education is the most effective mechanism for society to face the challenge of sustainable development. Nowadays, all countries, which are seeking the real development and reforms of the system, start the reforms from the education organization. This article focuses on training their teachers in the context of this approach. Moreover, development is a qualitative and long- 
term variable. In 1987, the International Commission for the Environment and Development (WCED), known as the "Brandenland Commission" defines it that "The sustainable development" should meet the current needs of the world and it won't endanger the ability of the future generations to meet their needs. (Growth Encyclopedia quoted in the European Union, 2013). In the sense of integrating economic, social, environmental goals, the sustainable development is to aim at maximizing the current welfare of the human being, without compromising the capabilities of future generations to meet their needs. (Soltanipour, 2016; 1). The sustainable development is the interconnection of human beings and nature throughout the world. The sustainable developments require holistic, systemic thinking, interdisciplinary and interdisciplinary, informed, creative people with participatory insights. The production of qualified human resources can be investigated in layers that are important in the form of a cyclical community (Naghdi and Sadeghi; 2000; 1-14). Training teacher is one of the key circles of this human resource education chain. In the sustainability of development, the goal is to establish a dynamic balance among the three components of the "economic", "social" and "biological" modules. The encyclopedia defines the growth of "economic development" as below:

The economic development means growth along with increasing production capacity including physical, human and social capacity."

The economic development follows two main objectives:

1- Increase the health and wealth of the community, and it will eradicate any kind of poverty.

2- Creation of employment. Both of these goals are in line with social justice.

From a social perspective, development means to provide people with appropriate opportunities to live better through access to educational, health, welfare, nutrition, housing, employment and so on. (Shaker; Ghalavandi: 2015.3). The foundation of development is based on social capital and knowledge-based economy. Common understanding or collective consciousness in a community, which people understand and appreciate, is the highest level of social capital that underlies development, and of course this will be gained through training. Fundamentally, people need to be educated and trained so that they can be socialized, and the process of education is a vital development that will not be achieved except its path. The diversity of specializations, the speed of development, the need for extended knowledge and communication can clarify the need for training concepts. SoltaniPoor believes that sustainable development is a step towards "preserving natural resources and preventing environmental degradation." He believes that he must identify all the factors that contribute to this program, and find the role of each one.

\section{The statement of the problem}

This paper examines the role of "The University of Farhangian" in sustainable development. The questions we are looking for in this research.

1. The courses of study at the Farhangian University in which students can enter, and it provides them with a tremendous amount of money. Can these fields of study be suitable for sustainable development in order to strengthen human resources?

2. Is the existing curriculum of this university and its revised content in line with strengthening the foundations of sustainable development?

Accordingly, to study the influential role of Farhangian University in sustainable development, this paper studies the sustainable development. Then, the teacher-training courses and the updated contents of Farhangian University are examined to analyze and evaluate the evidence needed for this sensation.

\section{Research method}

It is carried out in a three-level study by documentary research and development critique. 
The first level:

The theoretical subjects are studied and analyzed in a library and research.

After the decoding, the components of sustainable development are extracted (Output: 2017.54-57).

The second level:

A thorough study of the courses and content along with central coding are done on the content. The third level:

The location of the extracted components of the studies is reviewed in the syllabus, and the conceptualization occurs under the following concepts. Finally, the results are analyzed and some recommendations are done.

\section{Sustainable development and territorial development (educational)}

In this section, it is tried to focus on the basic discussion of development and education with a deep study of documents, books and articles, and the marks and codes of sustainable development are analyzed.

Sustainable development is the focus of human development. Therefore, as a human resource development agency, the university plays a supportive role in the path to sustainable development. (Karami et al., 93: 2012). Mehre Mohammadi (2013), Amin Khandaghi and Namkhah (2011), Dehghan, Mehram and Karami (2013).

They all emphasized with studying the curriculum on its importance in social development, and they emphasized it as one of the most important axes of development, that is, the teachertraining course. In researches, Khanifar (2004), Karami et al. (2012), Akbari et al. (2016) emphasized the impact of education and policies on academic education on its development. They also showed that universities can contribute significantly to the impact on the components of development. The academic education program in policy making along with its initiative, which is proposed as a major program in the 5th development plan, follow all these things purposefully. Some of the most important subjects in this project are as below:

Matching academic education development with provincial, national, regional and international needs, reviewing and developing curricula in line with academic education goals especially in the field of humanities. It includes revising subjects, levels, content of textbooks, developing theories of theater, structuring, creating quality assurance institutions and continuous monitoring of academic education, developing quantitative and qualitative structures and indicators of each sub-system, enhancing their effectiveness, empowering graduates, reviewing and organizing the role and mission of sub-systems. This issue that universities will prioritize which courses and curriculum content is a golden tip for the sustainability development. In accordance with the basic principles; the general and supplementary planning of education (Farjad, 1995; 25-37), education programs should be in line with the needs of national development. In this regard, a discussion of different planning approaches arises, and it is important in the context of territorial self-regulation. The initial definition of the arrangement can be found in the European Charter of the European Union of 1983 at the EC Ministers responsible for regional planning with this theme. It is the land of the scientific course, and it is an implementation method and a developed policy in the form of an interdisciplinary and comprehensive approach for balanced regional development and physical organizations. It can be a general strategy for policymakers and strategic planners (EU, 2013). It means management of the land; in fact, it is a kind of development planning whose objectives are social, economic, cultural and environmental organization, in order to achieve a desirable future. The concept of land planning, the creation of a balance between the three elements of man, space and activity is defined. (Soltani Pour; 2016, 1-14). The development plan, which is created through programing, is a prerequisite for the program. In other words, planning and arrangement is not a program, but it is an introduction or one of the program's implications. 
There is an objective and functional proportion between studies and policy models. The natural and climatic and environmental changes affect the planning of education. The benefits of the arrangement can be mentioned as follows:

The environmental and natural resources conservation - historic and costly preservation - cost savings - improved productivity and effectiveness - decentralization and poverty deprivation participation - strengthening the foundations of government in different countries (Land Plot Studies, 2004). You should not expect the costs to be repaid in the short term because it is a long-term process. Underdeveloped countries tend to copy the actions of more advanced countries, and in these countries, these policies may not have a 100\%-good result, because these programs are heavily dependent on the governance system of each country and how it is managed (either largely or federal, either free or dictatorial etc.). Failure to understand the various needs and expectations of people could overlook various plan for the reason that the needs and expectations of people are different.

Pseudo needs and fantasy needs make planners mistaken. It is a successful accomplishment of land planning when it is based on the geographic recognition of area. Understanding of natural data has a role such as topography, morphology, soil, climatic conditions, etc. (data and environmental capabilities such as plant, animal, underground resources, and in particular nonrenewable resources), assessment of productive forces, (Human resources structure) and other factors based on the adopted policies. In Iran, the program of academic education is introduced as a major program in the fifth development plan, and the syllabus of this program is set due to the importance of the impact of academic education on sustainable development. (Alt Bach, 1987). In a review of academic education issues in developing countries, Academic Education Organization is very important because it not only provides elite training and provides a basis for a technology-rich society, it is the most important intellectual system that influences culture, political and economic affairs (Soltani, 2011). However, the research studies did not get any traces of a training course in Teacher Training and Farhangian University. Nevertheless, the same study showing in the document of the fundamental transformation of education, which is an upstream document for this university; clearly does not refer to the necessity of using territorial arrangement. However, it follows goals that make sustainable development. According to the fundamental transformation document, it is a research-based document. As it takes advantages of the domestic experience, it benefits from international studies. The document addresses six major issues.

1. Religious and moral areas

2. Scientific and technological

3. Aesthetic art

4. Economic and professional

5. Physical and biological

6. Political and social ones under the sub-systems by Supreme leader, management and education.

All these materials come with teacher training and human resources, curriculum, research and evaluation, supply and allocation of finance, area, equipment and technology. It defines the environments at four levels.

1- Administrative, executive, government, general

2- Legal, Judicial, Provisional

3- Socio-economic, political, cultural

4. International (Neiaz Azeri et al.: 2011, 325-338)

In the analysis of this section, the environment has been ignored in the definition of other items. Obviously, the environment is mentioned in all parts of the documents.

However, if the territorial-dimension programming and educational planning is a prerequisite for sustainable development, and it is considered as a prerequisite for sustainable development, 
there has been no formal plans to train teachers. Apart from the goals of sustainable development, this category is observed in some parts of the handwritten documents. Meanwhile, judicial and security views are tangible in this category arrangement. Therefore, the development of the capacities of the University of farhangianl Sciences is essential as a productive and intermediary organization that serves academic education and ultimately society, and it is the proper use of the key role of the university.

\section{Introduction of Farhangian University and its courses}

Farhangian University officially started in 2012. This new university has a nearly hundred-year history and strong background of teacher training. At this time, the central organization of this university is based in Tehran, and it has

32 Campus for men (Pardis-e- bradaran) and 32 Campus for women (Pardis-e- khahran) in 31 provinces. Also, there is a center for cities in the province of Tehran. Conceivably, it is one of the few universities to keep up with the functional nature of the past with strong power based on community-based changes, and based on handwritten documents, especially national development plans. Based on the above documents, the main goal of the Farhangian University is to provide the specialist, skilled and professional, individual self-made researcher. This university has a good relationship with oneself, the creator, creation and people so that he will be able to achieve a higher level of life. The emphasis of this university is on the education of respectable, entrepreneurial, self-believable, creative and capable people to produce technology science and innovation commensurate with the needs of society based on national needs and the application of scientific and research achievements through dynamic and constructive interaction with the seminaries and internal, regional and international scientific and research centers.

The University of farhangian Sciences performs these important goals in two layers. First layer is to directly train the teaching-students, and the second layer is to indirectly train the future students of these teachers. Given what has been said, are the ultimate goals, which are set for this university, sustainable? The answer to this question needs a separate study to measure the distance between the ultimate goals and executive ones. The current profile of this university in Iran is like "a root in the soil", that is, "the credibility of the brilliant background" and the head rising in the sky" to the credit of the high goals as it defines." Farhangian University is a strategic; governance and mission-oriented university. This university seeks to achieve the goals of the Islamic Republic. In this regard, the compilation of its objectives is based on highranked manual documents. Farhangian University is an open social system. On the one hand, it focuses on the social environment in which it works, it has a great impact on science, education, services, culture, social, political and economic affairs. On the other hand, this university affects environmental changes. Therefore, the University of farhangian Sciences is a strategic one whose results have an exponential effect on society, and its society's sustainable development is directly related to the quality and quantity of its output. The emphasis on the application of advanced knowledge, the quality of knowledge, and the simultaneous supply quantity are very important. Currently, the university has a lot of fans among young job seekers and graduates of education, especially girls. The results of the national test and the presence of people with the desired outcomes of the examinations among applicants to enter this university could confirm the author's purpose. Some of the good students' incentives for recruitment include: definitive employment, related employment, native selection, student-education with salary, and boys' exemptions from military service. The award of these privileges, which impose a very academic cost on the system, is in line with the training of the teacher in the Islamic Republic of Iran, and it shows the importance of this job and its impact on society. Farhangian University accepts students from some educational groups such as math, human, 
experimental, art, and foreign language through the National University in the following fields each year.

From the Mathematics: mathematics - physics.

From the human course: Farsi language and literature, social sciences, guidance and consultation, theology and Islamic studies, geography education, Arabic language and literature.

From the experimental sciences: chemistry and biology.

In all three groups, Farhangian University accepts elementary education - physical education education for exceptional children.

From the language group, teaching English

From Art, video communication training

In total, this university attracts students in sixteen diverse fields. The largest attraction of this university belongs to the elementary school. It is emphasized here that there are no recruitments for vocational and professional courses except the field of art. With the efforts of university officials, the titles of syllabuses for existing courses are reviewed seriously. (Mashkibaf Maghqadam, Tâllây, Salavati, 2016). These items can be defined as a revolution in their own ways in the Iranian educational system. These content changes are approved by the Ministry of Science in 2014 for the elementary-school program, and other high school and junior-high school cases along with counseling course at the time of this research are ongoing and tracking. The scope of these changes in the field of curriculum including changing the title of courses and syllabuses in this article is intended and followed by the author. In addition to the positive points mentioned in the teacher's studies discussed above, the fields available at this university are very important, and furthermore they directly and indirectly can affect the sustainable development. Nonetheless, the point seeming very important is the opportunity of other courses which have early and robust impact on a strong start in sustainable development. The most important of these courses, which include the technical and vocational-teacher training, are for students intending to learn technical and vocational courses along with work and knowledge. For sustainable development in all aspects of social and biological aspects, the important factor is the economic boost which can somehow form other dimensions. The emphasis on the vocational and technical course is the most accessible way to this. Unfortunately, they are left behind, and they have never been seen in the programs of the University of farhangian Studies.

\section{Study of the course syllabus of different universities of Farhangian.}

The first major signs of these changes in the revised content are as below:

Reducing the number of theoretical units; and adding them to the practical units, defining workshop subjects and the milestone of that subject. The second important point in the field of the students is the case in the new research topics. Providentially, this category has been addressed in the new content. In these content, the teacher is seen as a dignified and thoughtful performer who is able to solve technical and procedural issues. In the new content of the subjects of this university, many have tried to link public knowledge to the local and personalized knowledge of the teacher, and they will validate the resulting knowledge. In order to achieve this, it uses various types of narrative researches; action researches; research activities and studies. That is to say, they somehow arrive at a kind of the personalized memory of students to the criticize ethnography. The curriculum of Farhangian University includes a formal curriculum, an incongruous curriculum and a hidden curriculum, and programs for their accommodation during their studies (area, structure, and communication). These categories contribute to the training of students and consequently the education of their future students. University officials said that this program insists on the complementary and informal programs. They point out the important factors in the program. Including multi fathangian education, sustainable development, creativity, entrepreneurship, environmental issues, intelligent and 
exceptional students, media literacy, film criticism, academic forums, etc. "They define its location potential as a dormitory and its time potential as leisure time. The same confession indicates that the sustainable development on the fringe of the official program has been considered by programmers, and it can be considered as an effective factor not a developmentoriented curriculum. Nonetheless in this case, this study focuses only on explicit curriculum planning or syllabus writing. The sixteen- course syllabus are reasonably categorized. The division of subjects includes a total of 150 curricula, 16 Islamic units, 11 general units, 15 Islamic education units, 18 educational units, and 28 vocational education units. These units are all students in different fields of the University of farhangian Studies. In the author's opinion, it works like a template for teaching. For all the courses described above, the structure and layout of the content have the same pattern. The subject is first introduced, the features are described, the goals and consequences are explained. A set of performance evaluation criteria are introduced at three levels 1, 2, and 3, and opportunities, learning and functional criteria are defined. The educational resources and evaluation strategies are presented separately. 62 specialized units are varied based on the field title. These content and consequently their content varies. These units, as specialized materials, can define the specialty of each field except for the elementary-school courses. They provide courses for other technical ones in their own courses.

\section{Steps to Run}

In this research, articles and books on sustainable development are studied. The texts are studied and analyzed and then are coded, and from the coding, the following categories are extracted for sustainable development. Items that are organized include:

Social sustainability, economic sustainability, organizational sustainability, environmental sustainability and technological sustainability, which are described below in terms of economic development, along with social and biological development. Then, in the general subjects of the whole course, the categories and keywords for sustainable development are searched. Some of the components are explicit and some implicit and invisible, but transitional ones are identified. The extracted components are presented in table 1 and 2.

Table 1: The Relationship between the Components of the Constant Development of Course Contexts clearly

\begin{tabular}{|c|c|c|c|c|c|c|}
\hline Course category & Components of Sustainable Development & 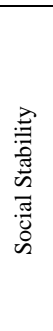 & 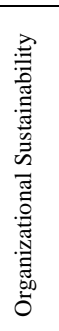 & 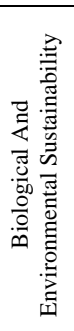 & 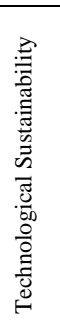 & \\
\hline $\begin{array}{l}16 \text { Islamic } \\
\text { teaching }\end{array}$ & - & - & - & - & & \\
\hline \multirow{3}{*}{$\begin{array}{l}15 \text { Islamic } \\
\text { education units }\end{array}$} & $\begin{array}{l}\text { Documents, Laws and Education Organization in } \\
\text { the Islamic Republic of Iran }\end{array}$ & $\checkmark$ & $\checkmark$ & - & - & \\
\hline & Teacher Professional Ethics & $\checkmark$ & $\checkmark$ & - & - & \\
\hline & $\begin{array}{l}\text { The social role of the teacher from the point of } \\
\text { view of Islam }\end{array}$ & $\checkmark$ & - & - & - & \\
\hline \multirow{2}{*}{ General } & Health and environmental protection & $\checkmark$ & - & $\checkmark$ & - & \\
\hline & Physical Education & $\checkmark$ & - & - & - & \\
\hline \multirow{2}{*}{$\begin{array}{l}\text { Educational } \\
\text { (PCK) }\end{array}$} & School Management & - & $\checkmark$ & - & - & \\
\hline & Educational sociology & $\checkmark$ & - & - & - & \\
\hline
\end{tabular}




\begin{tabular}{|c|c|c|c|c|c|c|}
\hline \multirow{7}{*}{$\begin{array}{l}\text { Physical } \\
\text { Education } \\
\text { (PCK) }\end{array}$} & $\begin{array}{l}\text { Application of Information and Communication } \\
\text { Technology } 1\end{array}$ & - & $\checkmark$ & & $\checkmark$ & \\
\hline & $\begin{array}{l}\text { Application of Information and Communication } \\
\text { Technology } 2\end{array}$ & - & $\checkmark$ & & $\checkmark$ & \\
\hline & $\begin{array}{l}\text { Application of Information and Communication } \\
\text { Technology } 3\end{array}$ & - & $\checkmark$ & - & $\checkmark$ & - \\
\hline & Training design in elementary education & - & - & - & $\checkmark$ & - \\
\hline & Research and Development 1: Narrative Research & $\checkmark$ & - & - & - & - \\
\hline & Research and Development 2: Research Activities & $\checkmark$ & $\checkmark$ & - & $\checkmark$ & \\
\hline & Research and Development 3: Study & $\checkmark$ & $\checkmark$ & & & \\
\hline
\end{tabular}

Table 2: The relationship between the components of sustainable development and the course syllabus implicitly and explicitly

\begin{tabular}{|c|c|c|c|c|c|c|c|}
\hline Course category & $\begin{array}{l}\text { Components of Sustainable } \\
\text { Development }\end{array}$ & 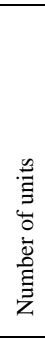 & 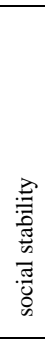 & 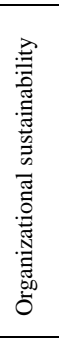 & 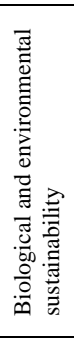 & 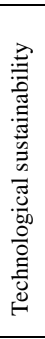 & 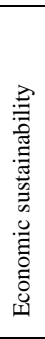 \\
\hline \multirow{2}{*}{16 Islamic education } & life style & 2 & $\checkmark$ & - & - & - & - \\
\hline & Family knowledge & 2 & $\checkmark$ & - & $\checkmark$ & - & \\
\hline \multirow{2}{*}{11 general units } & & 1 & - & $\checkmark$ & - & $\checkmark$ & - \\
\hline & Creative writing & 1 & - & $\checkmark$ & - & - & - \\
\hline \multirow{3}{*}{$\begin{array}{l}15 \text { units of Islamic } \\
\text { sport }\end{array}$} & Scientific writing & 3 & - & $\checkmark$ & - & - & \\
\hline & Islamic Educational System & 3 & $\checkmark$ & $\checkmark$ & $\checkmark$ & $\checkmark$ & $\checkmark$ \\
\hline & Philosophy of Education in JHA & 2 & $\checkmark$ & $\checkmark$ & $\checkmark$ & $\checkmark$ & $\checkmark$ \\
\hline \multirow{9}{*}{$\begin{array}{l}18 \text { units of education } \\
\text { (PCK) }\end{array}$} & $\begin{array}{l}\text { The philosophy of formal and general } \\
\text { education in JHA }\end{array}$ & 2 & - & $\checkmark$ & - & - & - \\
\hline & Principles and Methods of Teaching & 2 & $\checkmark$ & $\checkmark$ & - & $\checkmark$ & - \\
\hline & Principles of guidance and counseling & 2 & $\checkmark$ & $\checkmark$ & - & - & - \\
\hline & Educational Psychology & 2 & $\checkmark$ & $\checkmark$ & - & - & - \\
\hline & Internship 1 & 2 & $\checkmark$ & $\checkmark$ & - & - & - \\
\hline & Internship 2 & 2 & $\checkmark$ & $\checkmark$ & - & - & - \\
\hline & Internship 3 & 2 & $\checkmark$ & $\checkmark$ & - & - & - \\
\hline & Internship 4 & 1 & $\checkmark$ & $\checkmark$ & - & - & - \\
\hline & The use of language in education & 2 & $\checkmark$ & $\checkmark$ & - & - & \\
\hline
\end{tabular}

\section{Conclusion and Recommendations}

It is unfair to ignore the efforts of experts and specialists in the education of Iran and the university officials now because of the fundamental transformation in the teacher training system. On the other hand, it is too early to judge the results of the university's curriculum planning process; because the syllabus and content are about to be reviewed, the work of this review has not yet been completed. The results of this study showed that, since the program is not an application, it is an introduction or one of the program's implications. However, experts have not had any plans for the University of farhangian Sciences yet, or if done, no official announcement. This missing link has a significant effect on the rational and immediate development of goals at different macro and intermediate levels; and this item can display the deep distance between these levels. Considering the most important dimension of sustainable 
development, which is the economic dimension, and the way to strengthen professional technical staff; this university as a teacher-training unit for Iran's educational system has no serious plans. The results of this study show that among the five identified components of sustainable development, there is no mention of sustainable development components. Also, these results in the field of clear indications, Islamic subjects have no reference to the components of sustainable development. Islamic education courses focus only on the components of social and organizational sustainability. The public subjects focus on social and biological sustainability. The PCK specialist training courses focus on social, organizational, and technological sustainability. In this research, five of the components affecting sustainable development in the implicit and subtle indicators section are as follows.

In the subject of the social and biological sustainability, public subjects focus on organizational and technological sustainability, Islamic education curricula, while they try to emphasize the organizational sustainability towards all five components, and PCK's emphasis on social and organizational sustainability has little emphasis on economic sustainability. The specialized subjects of the courses, due to the fact that they have not yet been reviewed, are not investigated in this study. Therefore, it is advisable for future researchers to pay close attention to completing the course review process or during this review. They should have effective recommendations to planners and programmers. Except for the identified and selected components of this research, some of the other components of sustainable development are seen in the content; these are the subjects for further investigations.

The course syllabus show that the components and themes of sustainable development play an effective and significant role in the written curriculum document; but in general, this app is not development-oriented. In a sporadic way, there are persistent developmental effects in the content. The impact of these content on sustainable development is in the way of implementation and appraisal of the program. It is recommended that future researchers address those issues.

\section{References}

Akbari, Ahmad. Dehym, Javad Dehnavi, Mary (2016). The Role of Academic Education Policies in Realizing Sustainable Development Plans. Journal of Management and Accounting, Volume 2, Issue 3, Autumn 2016

Amin Khandaghi, Meaning. Nashkhah, Marzieh (2011). Explore the level of attention to the subject of teacher training curriculum in Iran.

Farjad, Mohammad Ali. (1995). The principles of curriculum planning. Sahab Publications. First Edition.

Gharlulo, Mehdi. Hosseini, Hadi (2006). The study of sustainable development factors. Geography Magazine and District Development. Number 8.

Karami, Morteza. Bahmanabadi, Somayeh. Ismaili, Arezu (2012). Optimal decision making structure in designing academic education curriculum. 9th year, Volume 2, Number 7.

Khannifar, Hussein (2004). Teaching and researching the most powerful means of development. National Conference on the Role of Education in Sustainable Development.

Khoroshi; Pouran (2016). Narrative Research. Published by Esfahan. First Edition.

Mehrmohammadi, Mahmoud (2013). Teacher Training Curriculum and its Participatory Executive Model; The Development Strategy for Teacher Education in Iran. The two-fold theory and practice in curriculum.

Meshkibaff, Moghadam . Zohereh; Tallaie ; fatemeh Salavat Atefeh (2016). Analyzing the content of the curriculum of the University of Farhangian in terms of attention to social harm 
and ways to prevent it. First National Conference; Social Sciences, Educational Sciences, Psychology and Social Security. Alborz

Neiaz Azeri, Kiomars. Esmaeili Shad, Behrang, Ribiee Dolabi, Majid (2011). Policymaking and the general process of teaching in the educational system. Mehr Aeeni Publications. First Edition.

Peasant, Abdul Majid. Mohammad, Behrouz Karami, Morteza (2014). Evaluation of curriculum in Farhangian University in terms of educating researcher teachers. Graduate study programs in academic education. Number 7.

Seyed Mohammadi, Mahmoud. Colleagues (2017). Curriculum of views, perspectives and perspectives. Fara Angizesh. Third book.

Shaker; Simin. Ghalavandi; Hasan (2015). Study of the relationship between self-efficacy and job burnout among employees of the University of Urmia in the academic year of 93-94; the third National Conference on Sustainable Development in Education Sciences and Psychology; Socio-Cultural Studies; Tehran; Islamic Studies Soroush; Center for Achieving Sustainable Development.

Short, Edmund C. (2013). Psychology of curriculum studies. Mehrmohammadi, Mahmoud. Curriculum Studies Organization (Samt). Third edition.

Soltani Pour, Farzaneh. Demari, Behzad (2016). Status of Sustainable Development in Iran. Journal of School of Public Health and Public Health Research. Winter; number fourteen;

Soltani, Omid (2011). Evaluation of Strategic Planning Relationship with the Flexibility of Academicer Education Institutions, Graduate Student of Allameh University.

Documents

1. The Articles of Association of the University of farhangian Professionals, approved by the Supreme Council of the farhangian Revolution

2. The Letter of the National Book of the Islamic Republic of Iran. 1988.

3. Curriculum, Continuing Master's Degree Program in Primary Education (Specialized University of farhangian Studies), Human Sciences, Revised 26 $\backslash 01 \backslash 1395$.

4. Management and Planning Organization (2004), Land Reclamation Studies, Office of Development and Sustainability, Tehran.

5. Revised Course of the University of Farhangian. 2014

6. The Transformation Document. 2011

7. Encyclopedia of growth http://danesh.roshd.ir. 